\title{
The neurobiology of methamphetamine induced psychosis
}

\section{Jennifer H. Hsieh *, Dan J. Stein and Fleur M. Howells*}

Department of Psychiatry and Mental Health, University of Cape Town, Western Cape, South Africa

\section{Edited by:}

Anneke E. Goudriaan, University of Amsterdam and Arkin Mental

Health, Netherlands

\section{Reviewed by:}

Gregg Stanwood, Vanderbilt

University, USA

Ali Mazaheri, University of

Amsterdam, USA

Nitya Jayaram-Lindstrom, Karolinska

Institutet, Sweden

\section{*Correspondence:}

Jennifer H. Hsieh, Department of

Psychiatry, University of Cape Town,

Office 110, J-2 Block Old Groote

Schuur Hospital, 7925, South Africa

e-mail: jennifer.hsieh@uct.ac.za;

Fleur M. Howells, Department of

Psychiatry, University of Cape Town,

Office 105, J-2 Block Old Groote

Schuur Hospital, South Africa

e-mail: howellsfleur@gmail.com
Chronic methamphetamine abuse commonly leads to psychosis, with positive and cognitive symptoms that are similar to those of schizophrenia. Methamphetamine induced psychosis (MAP) can persist and diagnoses of MAP often change to a diagnosis of schizophrenia over time. Studies in schizophrenia have found much evidence of cortical GABAergic dysfunction. Methamphetamine psychosis is a well studied model for schizophrenia, however there is little research on the effects of methamphetamine on cortical GABAergic function in the model, and the neurobiology of MAP is unknown. This paper reviews the effects of methamphetamine on dopaminergic pathways, with focus on its ability to increase glutamate release in the cortex. Excess cortical glutamate would likely damage GABAergic interneurons, and evidence of this disturbance as a result of methamphetamine treatment will be discussed. We propose that cortical GABAergic interneurons are particularly vulnerable to glutamate overflow as a result of subcellular location of NMDA receptors on interneurons in the cortex. Damage to cortical GABAergic function would lead to dysregulation of cortical signals, resulting in psychosis, and further support MAP as a model for schizophrenia.

\section{Keywords: schizophrenia, cortex, GABA, neurotoxicity, sensitization, neural circuitry}

\section{INTRODUCTION}

Methamphetamine is a lipophilic compound used recreationally for its ability to temporarily induce a variety of desirable effects, including increased energy levels, positive mood, euphoria, reduced appetite, weight loss, enhanced mental acuity, social, and sexual disinhibition (Cretzmeyer et al., 2003; Green and Halkitis, 2006; Cruickshank and Dyer, 2009).

According to the United Nations World Drug Report, between 0.3 and $1.3 \%$ of the world's population uses amphetaminetype stimulants (United Nations Office, 2011; Burns, 2014). Amphetamine abuse has a multitude of repercussions, including violence (Plüddemann et al., 2010) criminal behavior, incarceration, recidivism (Cartier et al., 2006), and the transmission of HIV (Halkitis et al., 2001; Colfax and Guzman, 2006).

Repeated administrations, or administration of high doses of methamphetamine, commonly leads to psychosis (Connell, 1958; Bell, 1965; Angrist and Gershon, 1970; Bell, 1973; Batki and Harris, 2004; Curran et al., 2004), where symptoms typically include paranoid delusions, auditory hallucinations, increased activity, and odd speech (Connell, 1958; Bramness et al., 2012). The prevalence of psychotic symptoms as a result of methamphetamine use can be difficult to determine as the diagnosis could be confused with that of a primary psychotic disorder, or other drug use (Weich and Pienaar, 2009; American Psychiatric Association, 2013). Depending on the study, the prevalence of psychosis in methamphetamine abusers ranges between 10 and 60\% (Farrell et al., 2002; McKetin et al., 2006; Mahoney et al., 2008). In Thailand, approximately $10 \%$ of admissions to psychiatric facilities are attributed to methamphetamine related psychosis (Farrell et al., 2002). An Australian study of 277 non-treatment-seeking illicit methamphetamine users with no prior diagnosis of schizophrenia or other psychotic disorders found that $51(18 \%)$ had "clinically significant" psychotic symptoms (McKetin et al., 2006), and a U.S. study of 42 cocainedependent and 43 methamphetamine-dependent individuals, screened to exclude patients with other axis I disorders, reported psychotic symptoms of at least some type in at least $60 \%$ of both groups (Mahoney et al., 2008). Recreational use of methamphetamine has been shown to increase the risk of developing psychotic symptoms by two to three fold (McKetin et al., 2010) especially if larger amounts of methamphetamine is used, or use began at a younger age (Chen et al., 2003).

Symptoms of MAP were originally thought to dissipate within a week of methamphetamine withdrawal (Connell, 1958). However, studies have shown that, although the large majority of MAP symptoms resolve within 1 month (Iwanami et al., 1994; Ujike and Sato, 2004; Deng et al., 2012), 30\% of those with MAP had symptoms persist for up to 6 months (Deng et al., 2012), and $10-28 \%$ reported persisting symptoms for more than 6 months (Iwanami et al., 1994; Deng et al., 2012). Symptoms of MAP have been shown to relapse after long periods of abstinence (Sato et al., 1992; Yui et al., 1997, 1999).

The DSM-V indicates that persistent psychosis after 6 months of abstinence from methamphetamine can constitute a diagnosis of schizophrenia (American Psychiatric Association, 2013). A recent Chinese study found that $5 \%$ of patients initially diagnosed with MAP had their diagnosis changed to schizophrenia in the interview conducted by the study (Deng et al., 2012). In Thailand, a similar study found that $38.8 \%$ of abstinent methamphetamine abusers who were initially hospitalized for 
MAP, were subsequently given a diagnosis of schizophrenia (Kittirattanapaiboon et al., 2010).

Whether there are fewer presentations of negative symptoms (lack of affect, social withdrawal) in MAP than schizophrenia (Tomiyama, 1990; Panenka et al., 2013), or whether both positive and negative symptom presentations are similar in MAP and schizophrenia (Srisurapanont et al., 2003, 2011), is still under debate. However, there is broad consensus that the positive symptoms of psychosis induced by methamphetamine use are difficult to distinguish from the positive symptoms of schizophrenia (Connell, 1958; Janowsky and Risch, 1979; Bramness et al., 2012; Medhus et al., 2013).

Clinical similarities between MAP and schizophrenia have long since been recognized (Connell, 1958). Various methamphetamine induced animal models for psychosis such as the neurotoxicity model (Robinson and Becker, 1986; Machiyama, 1992; Davidson et al., 2001; Cadet and Krasnova, 2009), the behavioral sensitization model (Castner and Goldman-Rakic, 1999; Featherstone et al., 2007), or the escalating dose-binge model (Segal and Kuczenski, 1997, 2001), have been proposed and debated for validity. Most relevant to this review is the methamphetamine sensitization model, where lower doses of repeated methamphetamine exposure have been shown to produce behavioral effects that best model psychosis by measurements such as increased locomotion, hallucinatory behaviors in the case of non-human primates, and deficits in pre-pulse inhibition, latent inhibition, and other cognitive measures in a variety of animal models (Castner and Goldman-Rakic, 1999; Kamei et al., 2006; Featherstone et al., 2007; Nagai et al., 2007; Forrest et al., 2014).

Schizophrenia has been associated with a wide variety of neurocognitive deficits e.g., in verbal memory, social cognition, implicit learning, and working memory, which impair day to day function (Green, 1996; Gold, 2004; Horan et al., 2008). Cognitive functions such as working memory rely on coherent interaction between interaction between interneurons and pyramidal cells, which form local memory fields, and "sharpen" signal to noise ratios (Goldman-Rakic, 1995). GABAergic interneurons in the cortex shape the stimulus response properties of pyramidal cells, and prevent aberrant firing of cortical processes (Jones, 1993). Evidence for GABA dysfunction in schizophrenia is convincing, and has been reviewed extensively (Goldman-Rakic, 1994; Lewis et al., 2004; Daskalakis et al., 2007; Lewis et al., 2012).

If MAP is to be a good model for schizophrenia, it should also exhibit similar cognitive impairments, and similar evidence of GABA disturbances as schizophrenia. In humans, MAP presents with similar cognitive impairments as those in schizophrenia, such as deficits in verbal and working memory, as well as other executive functions (Scott et al., 2007; Jacobs et al., 2008). In animal models, cognitive impairments have been found in using the amphetamine sensitization model in the non-human primate (Castner et al., 2005), and rodents (Nagai et al., 2007; Arai et al., 2009). Indeed, emerging evidence that will be discussed in this paper suggests that the cognitive deficits in MAP may also result from a GABAergic dysfunction in the cortex, although the mechanism for these observations are unknown.

The present paper will first describe the well characterized and relevant nigrostriatal, mesolimbic, and mesocortical pathways, on which methamphetamine exerts its major effects. Second, we will review the acute effects of methamphetamine and chronic effects of methamphetamine on these pathways. Next, studies that have shown cortical GABAergic disturbance will be discussed. Finally, we propose a possible vulnerability of GABAergic interneurons in the cortex to glutamate overflow, which might explain the GABAergic disturbance by methamphetamine that might lead to psychosis.

\section{NEUROCIRCUITRY OF THE CORTEX AND BASAL GANGLIA}

Methamphetamine appears to primarily affect the dopaminergic system. The present review will focus on the three main pathways, namely the nigrostriatal, mesolimbic, and mesocortical pathways, summarized in Figure 1.

The nigrostriatal pathway consists of the known direct and indirect pathways, which control the expression and direction of behavior to predictable stimuli or rewards (Balleine et al., 2007; Nicola, 2007). The mesolimbic pathway is involved in reward processing (Koob and Bloom, 1988), effort related functions (Salamone et al., 2007), translation of emotions into actions (Mogenson et al., 1980), and direction of behavior where stimuli and rewards are less predictable (Nicola, 2007). The mesocortical pathway is involved with cognitive functions such as working memory (Simon et al., 1980; Goldman-Rakic et al., 2004).

The majority (up to 77\%) of the striatum consists of GABAergic projection neurons (Graveland et al., 1985), that receive topographical input from the cortex (Kemp and Powell, 1970; Alexander and Crutcher, 1990; Haber and Knutson, 2010), and express $N$-methyl- $D$-aspartate (NMDA) receptors (Albin et al., 1992). The projection neurons comprises two major subpopulations. The striatonigral neurons, characterized by the expression of $\mathrm{D}_{1}$ receptors, project to the basal ganglial output nuclei, substantia nigra pars reticulata $(\mathrm{SNr}) /$ globus pallidus interna (GPi) (Altar and Hauser, 1987), the starting point of the direct pathway. The striatopallidal neurons, characterized by the expression of $\mathrm{D}_{2}$ receptors, project to the globus pallidus externa (GPe), and begin the indirect pathway. In the indirect pathway, neurons in the GPe send GABAergic projections to the subthalamic nucleus (STN), which send glutamatergic projections to activate the $\mathrm{SNr} / \mathrm{GPi}$. The $\mathrm{SNr}$ consists of tonically active GABAergic neurons that project to the thalamus (Reubi et al., 1977, 1978), and the thalamus projects via topographical glutamatergic neurons to the cortex (Haber and Knutson, 2010).

Since the SNr GABAergic neurons are tonically active (Reubi et al., 1977, 1978), there is normally little movement at rest, or minimal signaling to the cortex from the thalamus. In addition, up to $23 \%$ of striatal neurons are interneurons which have inhibitory effects on the projection neurons (Rymar et al., 2004), further inhibiting thalamocortical signals at rest (Reubi et al., 1977, 1978). Cortical glutamatergic activation of either the direct or indirect pathway primes the relevant pathway to an "upstate" (Wilson and Kawaguchi, 1996). From this "upstate," a small additional increase in activation by dopamine, released from the SNc, or a small decrease in inhibition by striatal cholinergic interneurons, will lead to the generation of action potentials that finally activate the primed pathway (Wilson, 1993; Tepper and Bolam, 2004). 


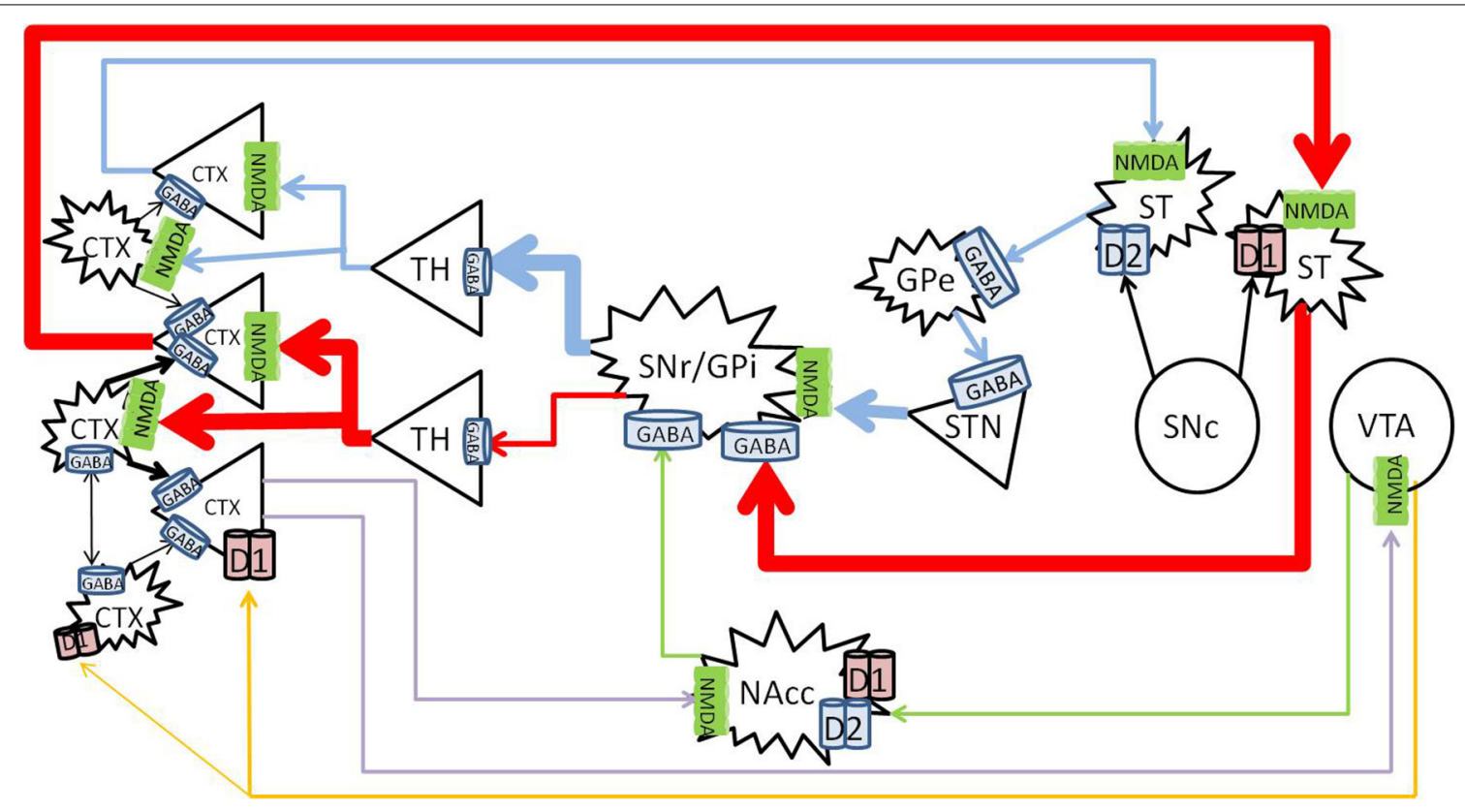

FIGURE 1 | Nigrostriatal, mesocortical, and mesolimbic pathways. When cortical neurons activate the NMDA receptors on neurons of the direct pathway (red) in the striatum, striatal neurons are primed to send GABA signals to the SNr/GPi, which would inhibit the tonic GABA to the thalamus, allow glutamate signals to fire in the cortex, and further activate cortical neurons. The indirect pathway (b/ue) is primed when cortical neurons activate the NMDA receptors on the striatal neurons that express $D_{2}$ receptors, which would send inhibitory signals to the globus pallidus externa $(\mathrm{GPe})$, reduce GABA signaling to the STN, and stimulate the SNr/GPi to enhance GABA inhibiting of thalamocortical signaling. The mesolimbic pathway (green) consist of dopaminergic projections from the VTA to the NAcc, which sends inhibitory signals to the SNr/GPi. The mesocortical pathway (orange) consists of dopaminergic projections from the VTA to the cortex, innervating both pyramidal and non-pyramidal neurons which express $D_{1}$ receptors. Reciprocal pathways (purple) from the cortex to the VTA and NAcc provide cortical feedback to subcortical structures. CTX, cortex; GABA, gamma-aminobutyric acid; NMDA, N-methyl-D-aspartate; GPe, globus pallidus externa; SNr, substantia nigra pars reticulata; GPi, globus pallidus interna; $\mathrm{TH}$, thalamus; STN, sub thalamic nucleus; NAcc, nucleus accumbens core; VTA, ventral tegmental area. Round structures indicate dopamine cell bodies; star shaped structures indicate GABA cell bodies; triangular structures indicate glutamate cell bodies.
Activation of the dopamine system enhances glutamate signaling in the cortex from the nigrostriatal and mesolimbic pathways, and increases dopamine in the prefrontal cortex from the mesocortical pathway (Figure 2).

Dopamine causes activation of neurons expressing $\mathrm{D}_{1}$ receptors, and inhibits neurons which express $\mathrm{D}_{2}$ receptors (Surmeier et al., 2007). In the nigrostriatal pathway, the synergistic activation of both the $D_{1}$ and $D_{2}$ receptors allows dopamine to enhance glutamate induced firing in the striatum (Hu and White, 1997). Thus, dopamine release into the striatum from the SNc enhances thalamocortical signals by simultaneously activating the direct pathway, and inhibiting the indirect pathway. Long term potentiation from this glutamatergic transmission leads to learning of the relevant activity, and the development of persistent behaviors (Yin and Knowlton, 2006; Balleine et al., 2007).

The mesolimbic pathway arises from dopaminergic ventral tegmental area (VTA) projections to the nucleus accumbens (NAc) (Fallon and Moore, 1978). The efferent projections of the NAc and afferent connections with other neuronal structures such as the amygdala, hippocampus and cortex are complex, and mediate its role in direction of behavior to emotive stimuli (Haber and McFarland, 1999; Haber and Knutson, 2010). Briefly, the NAc consists of "core" and "shell" regions, and one of the major effects of dopamine release at the NAc core is to increase GABA release to the $\mathrm{SNr} / \mathrm{GPi}$, disinhibiting the thalamus and increasing cortical glutamate (Maurice et al., 1999; Nicola, 2007).

The VTA and SN project to the cortex along the mesocortical pathway, and terminates on both pyramidal and non-pyramidal cells in the pre-frontal cortex (PFC) (Goldman-Rakic et al., 1989; Williams and Goldman-Rakic, 1998; Tzschentke, 2001). The expression of $D_{1}$ receptors is higher than that of $D_{2}$ in the cortex (Gaspar et al., 1995), and although more prevalent on pyramidal neurons, $D_{1}$ receptors are also widely expressed on GABAergic interneurons (Muly et al., 1998). Dopamine in the PFC serves a modulatory purpose and enhances $\mathrm{D}_{1}$ associated firing (Cepeda and Levine, 1998). Optimal levels of dopamine stimulates cortical GABAergic interneurons, which "tune" the pyramidal firing to sharpen pyramidal signals and enhances cognitive performance (Muly et al., 1998).

Cortical interneurons are predominantly GABAergic and prevent aberrant firing of cortical processes by shaping the receptive fields of thalamocorical signals (Jones, 1993). In addition, interneurons facilitate feed-forward inhibition, where a single thamalmic fiber can activate its pyramidal target as well as an interneuron, which will inhibit the pyramidal target within 1-10 ms, providing fine temporal control of pyramidal firing (Gabernet et al., 2005). These cells are necessary for inhibitory 


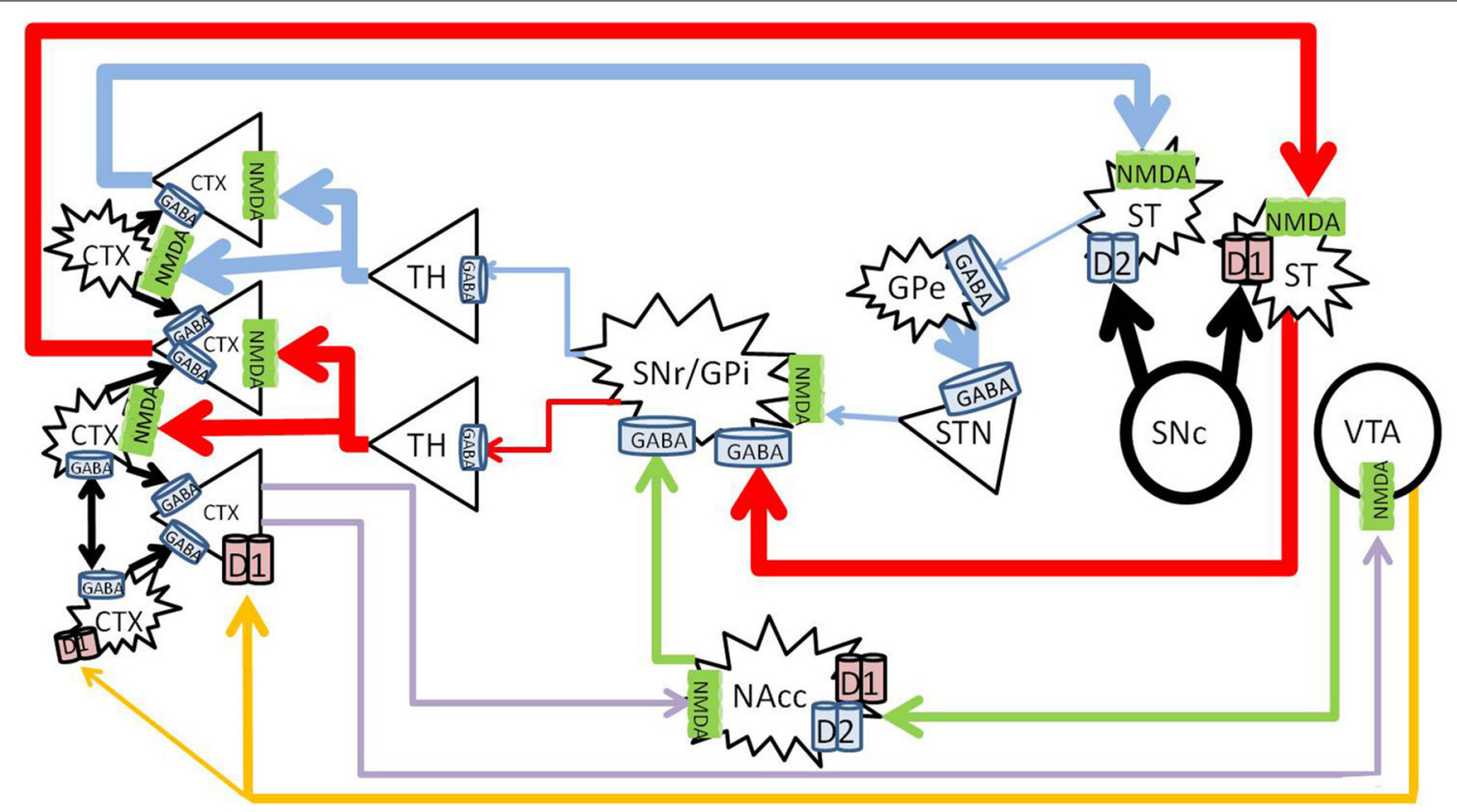

FIGURE 2 | Healthy effects of dopamine on dopaminergic pathways. The substantia nigra pars compacta (SNc) releases dopamine into the striatum (large black arrows), and enhances thalamocortical glutamate release along the nigrostriatal pathway (b/ue and red). The direct pathway (red) becomes enhanced by $D_{1}$ activation, and the indirect pathway (b/ue) becomes inhibited by $\mathrm{D}_{2}$ activation. Mesolimbic dopamine (green) to the NAc core increases GABA inhibition from the NAc core to the SNr/GPi, further increasing thalamocortical glutamate transmission. Mesocortical dopamine (orange) increases cortical pyramidal firing and simultaneously stimulates cortical interneurons, which sharpen the pyramidal signals to subcortical nuclei (blue, red, and purple). CTX, cortex; GABA, gamma-aminobutyric acid; NMDA, $\mathrm{N}$-methyl-D-aspartate; GPe, globus pallidus externa; $\mathrm{SNr}$, substantia nigra pars reticulata; GPi, globus pallidus interna; $\mathrm{TH}$, thalamus; STN, sub thalamic nucleus; NAcc, nucleus accumbens core; VTA, ventral tegmental area. Round structures indicate dopamine cell bodies; star shaped structures indicate GABA cell bodies; triangular structures indicate glutamate cell bodies. modulation, disinhibitory modulation, discriminative processing, gating of signals, as well as contribute in the generation of oscillatory rhythms that unify pyramidal cell discharge (Benes and Berretta, 2001).

\section{ACUTE EFFECTS OF METHAMPHETAMINE}

Acute methamphetamine administration causes vesicular release of dopamine from the VTA into the NAc and PFC in the mesolimbic and mesocortical pathways (Fallon and Moore, 1978; Haber and Knutson, 2010). Methamphetamine also reverses both vesicular monoamine transporter 2 and the dopamine transporter (Sulzer et al., 1995; Sora et al., 2009) to effectively increase synaptic concentrations of dopamine in the striatum in the nigrostriatal pathway (Bustamante et al., 2002; Fowler et al., 2008; Haber and Knutson, 2010) (Figure 3).

Acutely, methamphetamine increases levels of glutamate in the striatum (Stephans and Yamamoto, 1994) and the PFC (Stephans and Yamamoto, 1995). This is achieved via a polysynaptic process, where the increased dopamine release activates gamma-aminobutyric acid (GABA) neurons in the striatum of the direct pathway and increases GABA release at their terminals in the SNr. Presynaptic $D_{1}$ receptors on the striatonigral terminals (Altar and Hauser, 1987) also enhance GABA release at the SNr (Mark et al., 2004). The increased GABA at the SNr cell bodies disinhibit the thalamocortical glutamatergic pathway (Mark et al., 2004), which results in an increase of glutamate within the cortex
(Timmerman and Westerink, 1997). The high levels of glutamate at the level of the cortex activates the glutamatergic corticostriatal neurons via topographically specific postsynaptic density connections (Gerfen, 1989; Bellomo et al., 1998), and increases glutamate release in the striatum (Stephans and Yamamoto, 1994), driving positive feedback.

Glutamate levels in the striatum in fact remain elevated for over $28 \mathrm{~h}$, even after dopamine has returned to basal levels (Mark et al., 2004, 2007). It was found that the vesicular glutamate transporter 1 expression was increased, which allows for the sequestration of glutamate in the cortex, and thus allowing extended glutamate release into the striatum after methamphetamine administration (Mark et al., 2007). The NMDA receptors in the striatum facilitate $D_{1}$ receptor mediated currents, which positively drives this circuit.

Acute methamphetamine administration has been found to decrease $\mathrm{GABA}_{\mathrm{B}}$ transmission within the VTA (Padgett et al., 2012), and increases dopamine release from the VTA to the NAc (Fallon and Moore, 1978; Kankaanpää et al., 1998; Zhang et al., 2001). This release of dopamine in the mesolimbic pathway is associated with the experience of reward or euphoria (Volkow et al., 1996; Drevets et al., 2001), and increases subsequent GABA release to the substantia nigra for longer than $80 \mathrm{~min}$ (Sirinathsinghji et al., 1988). Inhibition of the SNr disinhibits the thalamocortical glutamatergic pathway, and results in increased cortical glutamate (Mark et al., 2004). 


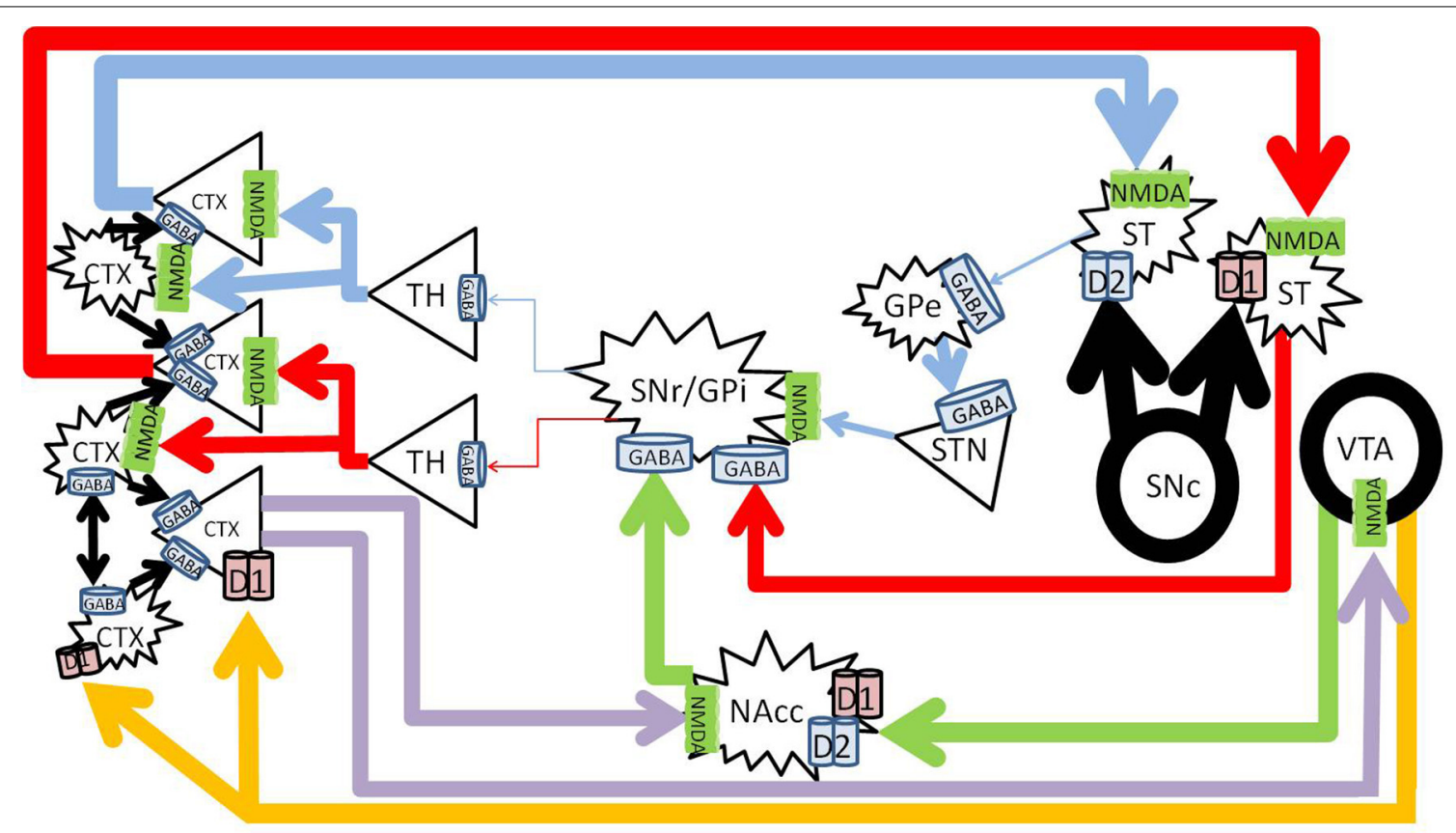

FIGURE 3 | Methamphetamine effects on dopaminergic pathways. Methamphetamine causes excessive amounts of dopamine to be released from the substantia nigra pars compacta (SNc) into the striatum (large black arrows), forcing pronounced inhibition of the SNr/GPi (red and blue). Dopamine from the VTA to the NAc increases NAc inhibition on the $\mathrm{SNr} / \mathrm{GPi}$ (green). Enhanced cortical signals increases glutamate from the PFC to the NAc (purple) further increasing NAc inhibition on the SNr/GPi, and exacerbates glutamate excess in the cortex. CTX, cortex; GABA, gamma-aminobutyric acid; NMDA, N-methyl-D-aspartate; GPe, globus pallidus externa; SNr, substantia nigra pars reticulata; GPi, globus pallidus interna; TH, thalamus; STN, sub thalamic nucleus; NAcc, nucleus accumbens core; VTA, ventral tegmental area. Round structures indicate dopamine cell bodies; star shaped structures indicate GABA cell bodies; triangular structures indicate glutamate cell bodies.
Methamphetamine also increases dopamine release from the VTA to the prefrontal cortex in the mesocortical pathway (Fallon and Moore, 1978; Stephans and Yamamoto, 1995). At low doses, methamphetamine can increase cognitive performance by activation of $\mathrm{D}_{1}$ receptors in the PFC (Silber et al., 2006), however high doses impair cognitive function (Schroder et al., 2003), possibly by over activation of $D_{1}$ receptors on interneurons in the PFC and excessive inhibition of cortical signals (Muly et al., 1998).

Methamphetamine can thus increase glutamatergic signals to the cortex from both the nigrostriatal, as well as the mesolimbic reward circuits, and increase dopaminergic signals from the mesocortical pathway. Excessive glutamate and dopamine in the cortex may overwhelm GABAergic interneuons, causing dysregulation of the signals, which may relate to the psychotic symptoms that can occur during methamphetamine intoxication in some individuals.

\section{CHRONIC METHAMPHETAMINE EFFECTS}

Studies in chronic methamphetamine abusers have found several changes in the brain, particularly within the striatum. A post mortem study found decreased levels of dopamine terminal markers such as dopamine, tyrosine hydroxylase, and dopamine transporter in the striatum (Wilson et al., 1996). Positron emission tomography research found decreased levels of the dopamine transporter (Volkow et al., 2001b), decreased $D_{2}$ (Volkow et al., 2001a) and decreased vesicular monoamine transporter 2 in the striatum (Chang et al., 2007). Single photon emission computed tomography studies have found decreased regional cerebral blood flow in chronic methamphetamine abusers (Iyo et al., 1997; Chung et al., 2010), magnetic resonance spectroscopy found decreased $N$-acetylaspartate (NAA) in the basal ganglia and frontal lobe (Ernst et al., 2000; Howells et al., 2014), and anterior cingulate (Nordahl et al., 2002; Howells et al., 2014) indicative of decreased neuronal integrity in these areas.

Participants with MAP have shown decreased P300 amplitude and increased P300 latency, particularly over the frontal cortex in electroencephalography (EEG) event related potential (ERP) studies, which suggests dysfunctional higher cognitive processing (Iwanami et al., 1991, 1993, 1998). Magnetic resonance spectroscopy showed decreased creatine and phosphocreatine to choline $(\mathrm{Cr}+\mathrm{PCr} / \mathrm{Cho})$ ratio in the basal ganglia that correlated significantly with increased residual psychiatric symptom severity (Sekine et al., 2002). Magnetic resonance imaging processed for voxel based morphometry found decreased frontopolar volumes compared to healthy controls (Aoki et al., 2013).

Various regimen of methamphetamine administration have developed different models for MAP and schizophrenia. The neurotoxicity model typically gave high doses of methamphetamine in a short amount of time, and found extensive neurotoxic damage, particularly to the nigrostriatal and mesolimbic systems (Robinson and Becker, 1986; Machiyama, 1992; Davidson et al., 2001; Cadet and Krasnova, 2009). However, it has been argued that the severe neurotoxicity produced by this model is not similar to the lack of obvious neurotoxic damage in people with MAP and schizophrenia, in addition methamphetamine abusers tend to begin with low doses of methamphetamine, which have 
shown to be neuroprotective to subsequent higher doses. Most relevant to this review is the methamphetamine sensitization model, where lower doses of repeated methamphetamine exposure have been shown to produce behavioral effects that best model psychosis by measurements such as increased locomotion, hallucinatory behaviors in the case of non-human primates, prepulse inhibition deficits, latent inhibition deficits, other cognitive deficits (Castner and Goldman-Rakic, 1999; Castner et al., 2000; Kamei et al., 2006; Featherstone et al., 2007; Nagai et al., 2007; Forrest et al., 2014). Although, the escalating dose-binge model also appears to model a widely used pattern of drug taking by abusers (Segal and Kuczenski, 1997, 2001).

Methamphetamine sensitized animals showed increased glutamate levels in the VTA 3 days after withdrawal (Giorgetti et al., 2002). The enhanced VTA activation increased release of dopamine in the NAc (Gonon, 1988) and dorsal striatum with a low dose amphetamine challenge after 28 days of withdrawal (Paulson and Robinson, 1995). Glutamate release was found to be increased in the NAc 2 days post withdrawal with low dose amphetamine challenge (Xue et al., 1996), or with $\mathrm{K}^{+}$depolarization 1 day post withdrawal (Bustamante et al., 2002). Studies in addiction have found that the increased sensitivity of the NAc to glutamate, and the increased glutamate release from the PFC to the NAc, mediates craving, and relapse in response to drug-related cues (Cornish and Kalivas, 2000; Kalivas and Volkow, 2005). Hyper-sensitivity of the NAc would further increase the activation of the NAc-thalamocortical circuit, and increase cortical glutamate (Maurice et al., 1999; Nicola, 2007).

Methamphetamine withdrawal after sensitization also exaggerated the inhibitory responses in the medial PFC, while augmenting excitatory responses in the ocular frontal cortex (Homayoun and Moghaddam, 2006). Morphological studies have found increased dendritic branching in the NAc and PFC of rodents approximately 1 month after methamphetamine sensitization (Robinson and Kolb, 1997, 1999), while a study in the dorsolateral PFC of non-human primates found decreased dendritic length and branching approximately 3 years after methamphetamine sensitization (Selemon et al., 2007). Twelve weeks of repeated low dose amphetamine exposure in rhesus monkeys showed reduced [123]IBZM displacement, and thus reduced dopamine release, in the striatum in response to a low dose amphetamine challenge about 30 days post withdrawal (Castner et al., 2000). Work on non-human primates has also shown that the cognitive deficits produced by methamphetamine sensitization are related to reduced dopaminergic turnover in the PFC and striatum (Castner et al., 2005), mediated by the D1ERK pathway dysfunction in the PFC (Nagai and Yamada, 2010).

While studies in the methamphetamine sensitization model of psychosis is extensive (Featherstone et al., 2007), few have examined the effects of chronic methamphetamine exposure on the cortical GABAergic system.

\section{CHRONIC METHAMPHETAMINE EFFECTS ON CORTICAL GABA}

Little research using any model has studied methamphetamine effects on GABA in the cortex, however there is some evidence which indicates that methamphetamine may indeed cause damage to cortical GABAergic interneurons.

Postmortem staining of the cortex in HIV positive methamphetamine users, compared to HIV positive non-users found extensive loss of calbindin immunoreactive interneurons in the cortex (Langford et al., 2003). Although co-morbid HIV and methamphetamine is known to compound neurodegenerative effects (Liu et al., 2009; Reiner et al., 2009), another group also found decreased calbindin immunoreactivity in cortical interneurons in rats that underwent an escalating dose, multiple binge exposure to methamphetamine, without the HIV confound (Kuczenski et al., 2007).

The escalating dose, multiple binge exposure of methamphetamine to the rats $(0.1 \mathrm{mg} / \mathrm{kg}$ escalated in $0.1 \mathrm{mg} / \mathrm{kg}$ increments 3 times a day, to $4 \mathrm{mg} / \mathrm{kg}$ over 14 days, then 4 injections of $6 \mathrm{mg} / \mathrm{kg}$ every $2 \mathrm{~h}$ for 11 successive days) in the Kuczenski et al. (2007) study deserves further discussion. The loss of calbindin immunoreactive interneurons was apparent from 3 days after last exposure to methamphetamine, and persisted when examined at 30 days post exposure. Pyramidal neurons and dendrites (marked by NeuN and MAP2 staining, respectively), were not significantly lost at 3 days post exposure, but were significantly reduced at 30 days post exposure, particularly in layers 2, 3, and 5 (Kuczenski et al., 2007). These results suggest a particular vulnerability of interneurons to methamphetamine administration, as compared to pyramidal neurons. The contrary observation of loss of pyramidal cells and dendrites in this study and the increased dendritic branching and spine densities in the PFC and NAc as seen in earlier studies (Robinson and Kolb, 1997, 1999) was not discussed. The Kuczenski study appears to be supported by the morphological study in non-human primates that showed decreased dendritic branching in the dorsolateral PFC 3 years post amphetamine sensitization (Selemon et al., 2007). Selemon et al. explained possible discrepancies between the primate study and Robinson's studies to species differences or interval of methamphetamine discontinuation, however the two rodent studies were both performed in Sprague-Dawley rats, and examined at 30 (Kuczenski et al., 2007) or 38 (Robinson and Kolb, 1997, 1999) days post exposure. In addition, the methamphetamine administration regimen was similar, where the Robinson and Kolb study escalated doses of $D$-amphetamine from 1 to $8 \mathrm{mg} / \mathrm{kg}$ for 5 weeks excluding weekends, and gave $8 \mathrm{mg} / \mathrm{kg}$ doses twice a day, $4 \mathrm{~h}$ apart for the last 4 days (Robinson and Kolb, 1997). Further work regarding methamphetamine effects on cortical morphometry may be helpful to clarify these discrepancies.

A toxicity study delivered a continuous high dose ( $32 \mathrm{mg} / \mathrm{kg} /$ day) of methamphetamine by implanted minipump in rats for 5 days (Armstrong and Noguchi, 2004). Autoradiography of $\mathrm{GABA}_{\mathrm{A}}$ sites labeled with $\left[{ }^{3} \mathrm{H}\right]$-Flunitrazepam showed that methamphetamine treatment caused a significant general decrease in staining on the entire hemi-brain, and significant decrease in the hippocampus. Other areas that were compared did not show significant decreases compared to drug naïve rats, although there was a general pattern of lower GABA binding in anterior cingulate, caudate, NAc, thalamus, and amygdala (Armstrong and Noguchi, 2004). Perhaps an increase in sample size to more than 8 rats in controls, and 7 rats in the 
methamphetamine treated group may have shown significant decreased $\left[{ }^{3} \mathrm{H}\right]$-Flunitrazepam binding in these areas.

More recent studies have found that methamphetamine sensitization in mice ( 4 injections of $2 \mathrm{mg} / \mathrm{kg}$, every other day) caused memory impairment, and autoradiography showed decreased $\left[{ }^{3} \mathrm{H}\right] \mathrm{MK}-801$ binding to NMDA receptors in the cortex, and hippocampus (Lee et al., 2011). Whether NMDA receptors that were lost were expressed on pyramidal or non-pyramidal neurons within the PFC is unclear, and the interval between last methamphetamine exposure and autoradiography was only $24 \mathrm{~h}$, immediately after the passive avoidance test (Lee et al., 2011).

A different mouse sensitization study $(1 \mathrm{mg} / \mathrm{kg}$ every day for 7 days) produced cognitive deficits that were ameliorated by the GABAB receptor agonist baclofen $(1-2 \mathrm{mg} / \mathrm{kg}$ acute dose) (Arai et al., 2009). Baclofen has also been shown to ameliorate methamphetamine induced pre-pulse inhibiton and object recognition memory deficits in mice (Mizoguchi and Yamada, 2011). Amphetamine induced dopamine release in the PFC is reduced by baclofen and SKF97541, which activate presynaptic GABA receptors on dopamine terminals (Balla et al., 2009).

A recent magnetic resonance spectroscopy study in methamphetamine sensitized rat brain dissections $(2.5 \mathrm{mg} / \mathrm{kg}$ twice per day over 7 days) showed decreased GABA, glutamate, and glutamine levels in the PFC ( $\mathrm{Bu}$ et al., 2013). Acute methamphetamine administration showed the ability to sequester glutamate in the cortex for over $28 \mathrm{~h}$ through upregulation of VGLUT1 (Mark et al., 2007). The Bu et al. study sacrificed the animals within $30 \mathrm{~min}$ of the last dose of methamphetamine and one might have expected to find increased glutamate levels in the prefrontal cortex. However, these authors suggest that the reduction in glutamate is likely due to higher demand, while the reduction in GABA was thought to be due both reduced glutamate as a substrate to form GABA, as well as increased GABA metabolism to succinic acid semialdehyde (which was found to be increased) (Bu et al., 2013).

Even though there is vast methodological variation in the above studies, each have shown evidence of cortical GABAergic deficit as a result of methamphetamine treatment. Damage to cortical GABAergic function could account for the cognitive impairments and persistent psychosis symptoms in MAP. The mechanism for this deficit is unknown. The present review proposes that there may be particular vulnerability of GABAergic interneurons, that might contribute to these observations of GABA dysfunction in the cortex as a result of methamphetamine exposure.

\section{CORTICAL GABAergic INTERNEURON VULNERABILITY}

The NMDA receptor is an ionotropic glutamate receptor that consists of a heterotetramer of two NR1 and two NR2 subunits, and mediates excitatory post-synaptic potentials (Dingledine et al., 1999). NMDA receptors are distributed widely throughout the nervous system (Petralia et al., 1994b).

The downstream effect of NMDA receptor function is highly dependent on the location of the receptors. The expression of $N$-methyl- $D$-aspartate (NMDA) receptors on postsynaptic pyramidal neurons leads to activation of the glutamatergic system and downstream neuronal activation. The expression of NMDA receptors on GABAergic interneurons results in a release of GABA, and has a downstream inhibitory effect. Thus, activation of NMDA receptors on pyramidal neurons leads to further release of glutamate, thereby providing positive feedback; while activation of NMDA receptors on interneurons leads to GABA release and regulation of glutamatergic function.

Pyramidal neurons in the cortex primarily express NMDA receptors at the somatic membrane, and proximal dendrites and in post synaptic densities (Aoki et al., 1994; Petralia et al., 1994a), with decreased expression at more distal dendrites (Huntley et al., 1994). Cortical GABAergic interneurons have typically multipolar aspiny dendrites (Kawaguchi, 1995; DeFelipe, 2001), with the majority of NMDA receptors expressed on the dendrites, not close to obvious post synaptic densities (Goldberg et al., 2003a,b) (Figure 4). Dense patterns of NMDAR1 staining appear particularly in the neuropil of layer II and III in the cortex (Aoki et al., 1994; Huntley et al., 1994), which coincide with the dense dendritic projections of basket, chandelier, and double bouquet type interneurons in this region (Benes and Berretta, 2001; DeFelipe, 2001; Gentet, 2012). Discussions of the various types, morphology, and physiological characterizations of GABAergic interneurons are interesting but not within the scope of this paper, and have been have been thoroughly reviewed elsewhere (Benes and Berretta, 2001; DeFelipe, 2001; Gentet, 2012).

The predominance of synaptic NMDA receptors on the pyramidal neurons, and extrasynaptic NMDA receptors on GABAergic interneurons differentiates their vulnerability to neurotoxicity (Papadia and Hardingham, 2007). Synaptic and extrasynaptic NMDA receptors have opposite effects regarding cAMP response element binding protein (CREB) function, gene regulation, and neuron survival (Hardingham et al., 2002). Calcium ion entry through synaptic NMDA receptors induces CREB activity and brain derived neurotrophic factor (BDNF) gene expression as strongly as those caused by direct stimulation of L-type calcium channels. In contrast, calcium ion entry

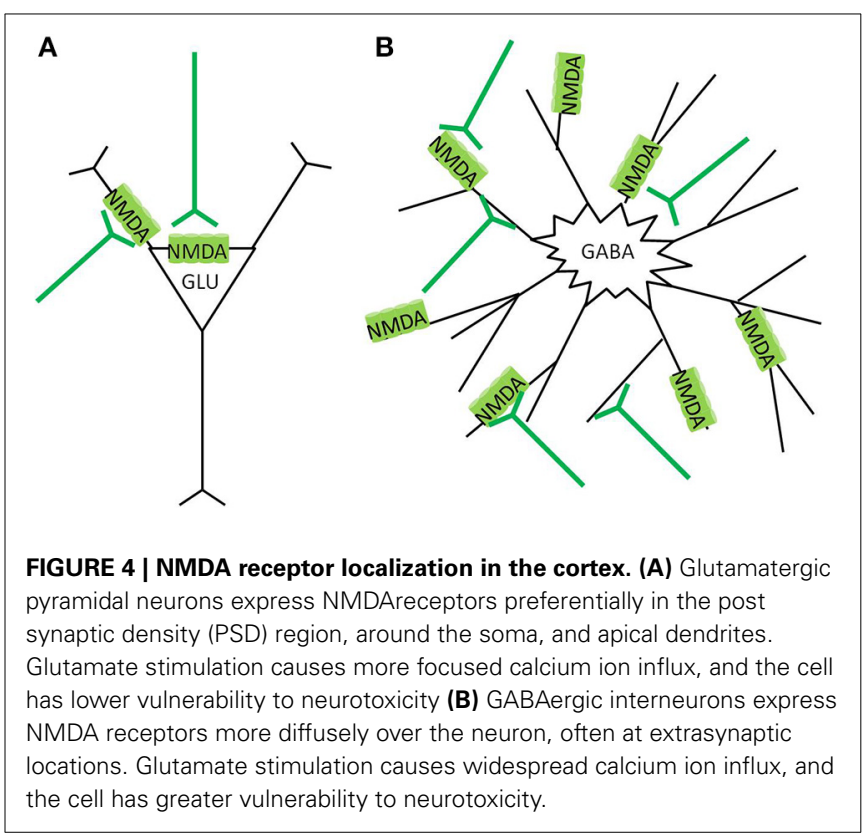




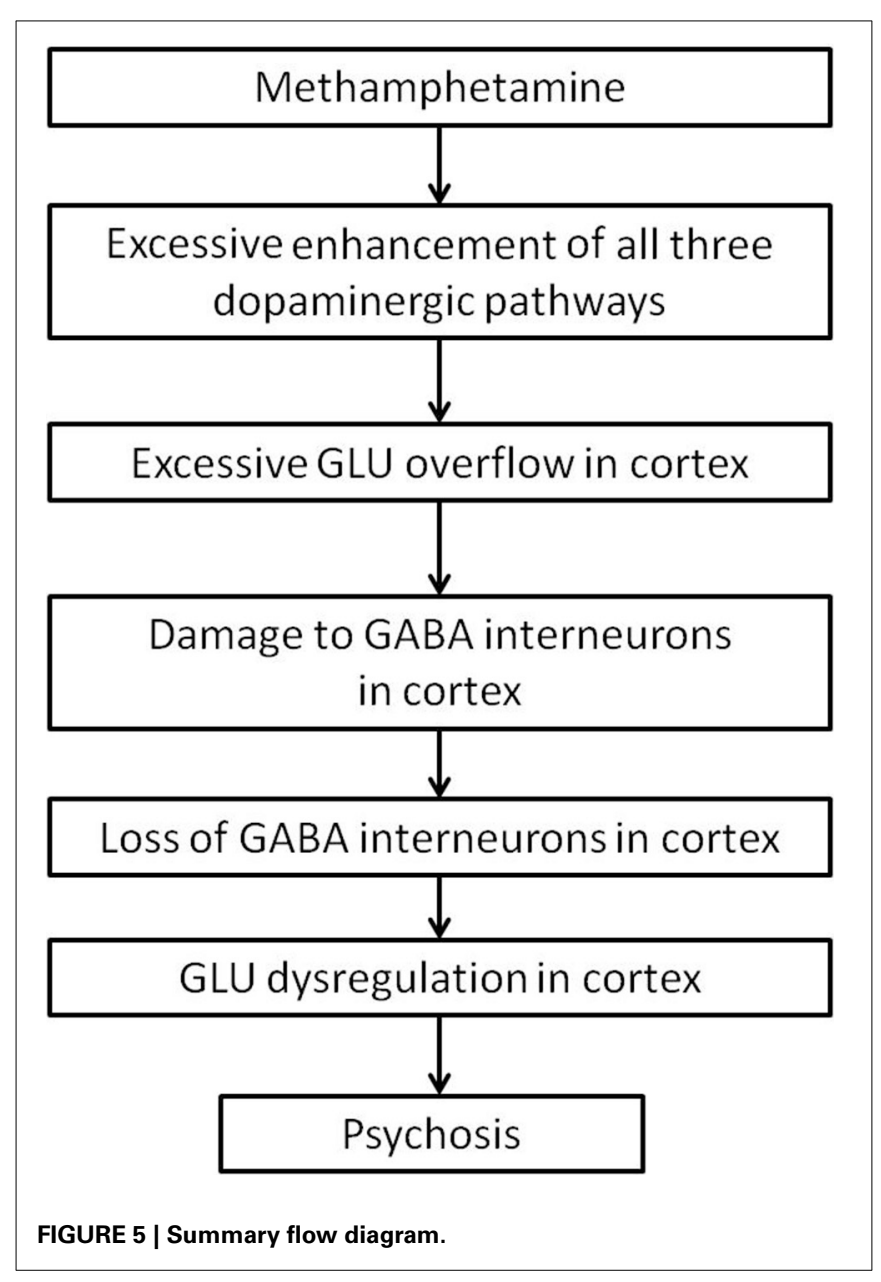

through extrasynaptic NMDA receptors, triggered by bath glutamate exposure or hypoxic conditions, activates a dominant pathway that blocks CREB and thus BDNF expression. In essence, synaptic NMDA receptors, mostly localized on glutamatergic cells, have anti-apoptotic activity, whereas stimulation of extrasynaptic NMDA receptors on interneurons results in glutamateinduced excitotoxicity (Hardingham et al., 2002). Similar CREB inhibiting effects have been found by activation of extrasynaptic NMDA receptors in co-cultured cortical glutamatergic and striatal GABAergic neurons, while synaptic NMDA activation on GABAergic striatal neurons was neuroprotective (Kaufman et al., 2012). Details of the mechanisms of the dicotomous effects of synaptic vs. extrasynaptic NMDA receptor activation is reviewed elsewhere (Papadia and Hardingham, 2007; Hardingham and Bading, 2010). Essentially, lower levels and specific activation of synaptic NMDA receptors promote neuroprotection and inhibits apoptotic pathways; while bath stimulation or over spill from high level stimulation cause extrasynaptic NMDA receptor activation, which not only inhibits CREB and BDNF expression, but also promotes a variety of other pro-death cascades (Papadia and Hardingham, 2007; Hardingham and Bading, 2010; Petralia, 2012).

Activation of predominantly extrasynaptic NMDA receptors on GABAergic interneurons would make these cells more vulnerable to neurotoxicity than pyramidal neurons. Thus, persistent glutamate overflow from the overstimulated thalamus and NAc to the cortex from repeated methamphetamine administration might lead to accelerated damage to interneurons compared to pyramidal neurons. Indeed, an escalating dose multiple binge regimen of methamphetamine administration in rats found that calbindin stained cortical interneurons were more sensitive to methamphetamine toxicity than their NeuN stained pyramidal neurons, as the interneurons were significantly lost from 3 days after the last methamphetamine binge dose, whereas the pyramidal neurons were lost only 30 days after the last dose (Kuczenski et al., 2007). Damage to cortical interneurons would diminish the negative feedback on pyramidal neurons, and result in increased subsequent pyramidal firing.

Cortical GABAergic interneurons synchronize cortical processes (Jones, 1993; Benes and Berretta, 2001). Damage to these neurons, whether by methamphetamine induced neurotoxicity, developmental defect, or other mechanisms would dysregulate glutamate signaling in the cortex. Even transient inhibition of NMDA receptors by a dose of MK-801 that impaired working memory in rats decreased organized bursting activity and increased the number of irregularly discharged single spikes from prefrontal pyramidal neurons (Jackson et al., 2004). Aberrant glutamate signals transmitted through the cortico-striatalthalamo-cortical loop may result in aberrant behaviors, and psychosis.

\section{SUMMARY}

The development of MAP might ultimately be due to damage of cortical interneurons. Cortical interneurons are likely more vulnerable to neurotoxicity, as they have a higher proportion of extrasynaptically expressed NMDA receptors. Methamphetamine use causes an overflow of dopamine in the striatum, which leads to excessive glutamate release into the cortex. Excess glutamate in the cortex might, over time, cause damage to cortical interneurons. Damage to cortical interneurons dysregulate thalamocortical signals, and might result in the presentation of psychotic symptoms as seen in schizophrenia (Figure 5).

Studies of GABAergic disturbance in the cortex as a result of methamphetamine have been presented, however further studies that directly compare cell type vulnerabilities to synaptic or extrasynaptic stimulation, as well as measurements of GABA concentrations, receptor expression and sensitivity in the cortex as a result of methamphetamine sensitization or psychosis, would be required to test this hypothesis.

\section{REFERENCES}

Albin, R. L., Makowiec, R. L., Hollingsworth, Z. R., Dure, L. S. 4th., Penney, J. B., and Young, A. B. (1992). Excitatory amino acid binding sites in the basal ganglia of the rat: a quantitative autoradiographic study. Neuroscience 46, 35-48. doi: 10.1016/0306-4522(92)90006-N

Alexander, G. E., and Crutcher, M. D. (1990). Functional architecture of basal ganglia circuits: neural substrates of parallel processing. Trends Neurosci. 13, 266-271. doi: 10.1016/0166-2236(90)90107-L

Altar, C. A., and Hauser, K. (1987). Topography of substantia nigra innervation by $\mathrm{d} 1$ receptor-containing striatal neurons. Brain Res. 410, 1-11. doi: 10.1016/S0006-8993(87)80014-8

American Psychiatric Association. (2013). DSM 5. Washington, DC: American Psychiatric Association. 
Angrist, B. M., and Gershon, S. (1970). The phenomenology of experimentally induced amphetamine psychosis-preliminary observations. Biol. Psychiatry 2, 95-107.

Aoki, C., Venkatesan, C., Go, C., Mong, J. A., and Dawson, T. M. (1994). Cellular and subcellular localization of nmda-rl subunit immunoreactivity in the visual cortex of adult and neonatal rats. J. Neurosci. 14, 5202-5222.

Aoki, Y., Orikabe, L., Takayanagi, Y., Yahata, N., Mozue, Y., Sudo, Y., et al. (2013). Volume reductions in frontopolar and left perisylvian cortices in methamphetamine induced psychosis. Schizophr. Res. 147, 355-361. doi: 10.1016/j. schres.2013.04.029

Arai, S., Takuma, K., Mizoguchi, H., Ibi, D., Nagai, T., Kamei, H., et al. (2009). Gabab receptor agonist baclofen improves methamphetamine-induced cognitive deficit in mice. Eur. J. Pharmacol. 602, 101-104. doi: 10.1016/j.ejphar.2008. 10.065

Armstrong, B. D., and Noguchi, K. K. (2004). The neurotoxic effects of 3,4methylenedioxymethamphetamine (mdma) and methamphetamine on serotonin, dopamine, and gaba-ergic terminals: an in-vitro autoradiographic study in rats. Neurotoxicology 25, 905-914. doi: 10.1016/j.neuro.2004.06.003

Balla, A., Nattini, M. E., Sershen, H., Lajtha, A., Dunlop, D. S., and Javitt, D. C. (2009). Gabab/nmda receptor interaction in the regulation of extracellular dopamine levels in rodent prefrontal cortex and striatum. Neuropharmacology 56, 915-921. doi: 10.1016/j.neuropharm.2009.01.021

Balleine, B. W., Delgado, M. R., and Hikosaka, O. (2007). The role of the dorsal striatum in reward and decision-making. J. Neurosci. 27, 8161-8165. doi: 10.1523/JNEUROSCI.1554-07.2007

Batki, S. L., and Harris, D. S. (2004). Quantitative drug levels in stimulant psychosis: relationship to symptom severity, catecholamines and hyperkinesia. Am. J. Addict. 13, 461-470. doi: 10.1080/10550490490512834

Bell, D. S. (1965). Comparison of amphetamine psychosis and schizophrenia. Br. J. Psychiatry 111, 701-707. doi: 10.1192/bjp.111.477.701

Bell, D. S. (1973). The experimental reproduction of amphetamine psychosis. Arch. Gen. Psychiatry 29, 35-40. doi: 10.1001/archpsyc.1973.04200010020003

Bellomo, M., Giuffrida, R., Palmeri, A., and Sapienza, S. (1998). Excitatory amino acids as neurotransmitters of corticostriatal projections: immunocytochemical evidence in the rat. Arch. Ital. Biol. 136, 215-223.

Benes, F. M., and Berretta, S. (2001). Gabaergic interneurons: implications for understanding schizophrenia and bipolar disorder. Neuropsychopharmacology 25, 1-27. doi: 10.1016/S0893-133X(01)00225-1

Bramness, J. G., Gundersen, O. H., Guterstam, J., Rognli, E. B., Konstenius, M., Loberg, E. M., et al. (2012). Amphetamine-induced psychosis-a separate diagnostic entity or primary psychosis triggered in the vulnerable? BMC Psychiatry 12:221. doi: 10.1186/1471-244X-12-221

Bu, Q., Lv, L., Yan, G., Deng, P., Wang, Y., Zhou, J., et al. (2013). Nmrbased metabonomic in hippocampus, nucleus accumbens and prefrontal cortex of methamphetamine-sensitized rats. Neurotoxicology 36, 17-23. doi: 10.1016/j.neuro.2013.02.007

Burns, L. (2014). World drug report 2013 by united nations office on drugs and crime new york: United nations, 2013isbn: 978-92-1-056168-6, 151 pp. grey literature. Drug Alcohol Rev. 33, 216-216. doi: 10.1111/dar.12110

Bustamante, D., You, Z.-B., Castel, M.-N., Johansson, S., Goiny, M., Terenius, L., et al. (2002). Effect of single and repeated methamphetamine treatment on neurotransmitter release in substantia nigra and neostriatum of the rat. $J$. Neurochem. 83, 645-654. doi: 10.1046/j.1471-4159.2002.01171.x

Cadet, J. L., and Krasnova, I. N. (2009). Molecular bases of methamphetamineinduced neurodegeneration. Int. Rev. Neurobiol. 88, 101-119. doi: 10.1016/S0074-7742(09)88005-7

Cartier, J., Farabee, D., and Prendergast, M. L. (2006). Methamphetamine use, self-reported violent crime, and recidivism among offenders in california who abuse substances. J. Interpers. Violence 21, 435-445. doi: 10.1177/088626050 5285724

Castner, S. A., al Tikriti, M. S., Baldwin, R. M., Seibyl, J. P., Innis, R. B., and Goldman-Rakic, P. S. (2000). Behavioral changes and [123i]ibzm equilibrium spect measurement of amphetamine-induced dopamine release in rhesus monkeys exposed to subchronic amphetamine. Neuropsychopharmacology 22, 4-13. doi: 10.1016/S0893-133X(99)00080-9

Castner, S. A., and Goldman-Rakic, P. S. (1999). Long-lasting psychotomimetic consequences of repeated low-dose amphetamine exposure in rhesus monkeys. Neuropsychopharmacology 20, 10-28. doi: 10.1016/S0893-133X(98) 00050-5
Castner, S. A., Vosler, P. S., and Goldman-Rakic, P. S. (2005). Amphetamine sensitization impairs cognition and reduces dopamine turnover in primate prefrontal cortex. Biol. Psychiatry 57, 743-751. doi: 10.1016/j.biopsych.2004. 12.019

Cepeda, C., and Levine, M. S. (1998). Dopamine and n-methyl-d-aspartate receptor interactions in the neostriatum. Dev. Neurosci. 20, 1-18. doi: $10.1159 / 000017294$

Chang, L., Alicata, D., Ernst, T., and Volkow, N. (2007). Structural and metabolic brain changes in the striatum associated with methamphetamine abuse. Addiction 102(Suppl. 1), 16-32. doi: 10.1111/j.1360-0443.2006.01782.x

Chen, C. K., Lin, S. K., Sham, P. C., Ball, D., Loh, E. W., Hsiao, C. C., et al. (2003). Pre-morbid characteristics and co-morbidity of methamphetamine users with and without psychosis. Psychol. Med. 33, 1407-1414. doi: 10.1017/S0033291703008353

Chung, Y. A., Peterson, B. S., Yoon, S. J., Cho, S. N., Chai, S., Jeong, J., et al. (2010). In vivo evidence for long-term cns toxicity, associated with chronic binge use of methamphetamine. Drug Alcohol Depend. 111, 155-160. doi: 10.1016/j.drugalcdep.2010.04.005

Colfax, G., and Guzman, R. (2006). Club drugs and hiv infection: a review. Clin. Infect. Dis. 42, 1463-1469. doi: 10.1086/503259

Connell, P. H. (1958). Amphetamine Psychosis. London: Chapman \& Hall.

Cornish, J. L., and Kalivas, P. W. (2000). Glutamate transmission in the nucleus accumbens mediates relapse in cocaine addiction. J. Neurosci. 20:RC89.

Cretzmeyer, M., Sarrazin, M. V., Huber, D. L., Block, R. I., and Hall, J. A. (2003). Treatment of methamphetamine abuse: research findings and clinical directions. J. Subst. Abuse Treat. 24, 267-277. doi: 10.1016/S0740-5472(03)00028-X

Cruickshank, C. C., and Dyer, K. R. (2009). A review of the clinical pharmacology of methamphetamine. Addiction 104, 1085-1099. doi: 10.1111/j.13600443.2009.02564.x

Curran, C., Byrappa, N., and McBride, A. (2004). Stimulant psychosis: systematic review. Br. J. Psychiatry 185, 196-204. doi: 10.1192/bjp.185.3.196

Daskalakis, Z. J., Fitzgerald, P. B., and Christensen, B. K. (2007). The role of cortical inhibition in the pathophysiology and treatment of schizophrenia. Brain Res. Rev. 56, 427-442. doi: 10.1016/j.brainresrev.2007.09.006

Davidson, C., Gow, A. J., Lee, T. H., and Ellinwood, E. H. (2001) Methamphetamine neurotoxicity: necrotic and apoptotic mechanisms and relevance to human abuse and treatment. Brain Res. Brain Res. Rev. 36, 1-22. doi: 10.1016/S0165-0173(01)00054-6

DeFelipe, J. (2001). Cortical interneurons: from cajal to 2001. Progress Brain Res. 136, 215-238. doi: 10.1016/S0079-6123(02)36019-9

Deng, X., Huang, Z., Li, X., Li, Y., Wang, Y., Wu, D., et al. (2012). Long-term follow-up of patients treated for psychotic symptoms that persist after stopping illicit drug use. Shanghai Arch. Psychiatry 24, 271-278. doi: 10.3969/j.issn.10020829.2012.05.004

Dingledine, R., Borges, K., Bowie, D., and Traynelis, S. F. (1999). The glutamate receptor ion channels. Pharmacol. Rev. 51, 7-61.

Drevets, W. C., Gautier, C., Price, J. C., Kupfer, D. J., Kinahan, P. E., Grace, A. A., et al. (2001). Amphetamine-induced dopamine release in human ventral striatum correlates with euphoria. Biol. Psychiatry 49, 81-96. doi: 10.1016/S00063223(00)01038-6

Ernst, T., Chang, L., Leonido-Yee, M., and Speck, O. (2000). Evidence for longterm neurotoxicity associated with methamphetamine abuse: a $1 \mathrm{~h}$ mrs study. Neurology 54, 1344-1349. doi: 10.1212/WNL.54.6.1344

Fallon, J. H., and Moore, R. Y. (1978). Catecholamine innervation of the basal forebrain iv. topography of the dopamine projection to the basal forebrain and neostriatum. J. Comp. Neurol. 180, 545-579. doi: 10.1002/cne.901800310

Farrell, M., Marsden, J., Ali, R., and Ling, W. (2002). Methamphetamine: drug use and psychoses becomes a major public health issue in the asia pacific region. Addiction 97, 771-772. doi: 10.1046/j.1360-0443.2002.00195.x

Featherstone, R., Kapur, S., and Fletcher, P. (2007). The amphetamine-induced sensitized state as a model of schizophrenia. Prog. Neuro-Psychopharmacol. Biol. Psychiatry 31, 1556-1571. doi: 10.1016/j.pnpbp.2007.08.025

Forrest, A. D., Coto, C. A., and Siegel, S. J. (2014). Animal models of psychosis: current state and future directions. Curr. Behav. Neurosci. Rep. 1, 100-116. doi: 10.1007/s40473-014-0013-2

Fowler, J. S., Volkow, N. D., Logan, J., Alexoff, D., Telang, F., Wang, G. J., et al. (2008). Fast uptake and long-lasting binding of methamphetamine in the human brain: comparison with cocaine. Neuroimage 43, 756-763. doi: 10.1016/j.neuroimage.2008.07.020 
Gabernet, L., Jadhav, S. P., Feldman, D. E., Carandini, M., and Scanziani, M. (2005). Somatosensory integration controlled by dynamic thalamocortical feedforward inhibition. Neuron 48, 315-327. doi: 10.1016/j.neuron.2005.09.022

Gaspar, P., Bloch, B., and Moine, C. (1995). D1 and d2 receptor gene expression in the rat frontal cortex: cellular localization in different classes of efferent neurons. Eur. J. Neurosci. 7, 1050-1063. doi: 10.1111/j.1460-9568.1995.tb01092.x

Gentet, L. J. (2012). Functional diversity of supragranular gabaergic neurons in the barrel cortex. Front. Neural Circuits 6:52. doi: 10.3389/fncir.2012.00052

Gerfen, C. R. (1989). The neostriatal mosaic: striatal patch-matrix organization is related to cortical lamination. Science 246, 385-388. doi: 10.1126/science. 2799392

Giorgetti, M., Hotsenpiller, G., Froestl, W., and Wolf, M. (2002). In vivo modulation of ventral tegmental area dopamine and glutamate efflux by local gaba $b$ receptors is altered after repeated amphetamine treatment. Neuroscience 109, 585-595. doi: 10.1016/S0306-4522(01)00510-3

Gold, J. M. (2004). Cognitive deficits as treatment targets in schizophrenia. Schizophr. Res. 72, 21-28. doi: 10.1016/j.schres.2004.09.008

Goldberg, J. H., Tamas, G., Aronov, D., and Yuste, R. (2003a). Calcium microdomains in aspiny dendrites. Neuron 40, 807-821. doi: 10.1016/S08966273(03)00714-1

Goldberg, J. H., Yuste, R., and Tamas, G. (2003b). Ca2+ imaging of mouse neocortical interneurone dendrites: contribution of ca2+-permeable ampa and nmda receptors to subthreshold ca2+dynamics. J. Physiol. 551 (pt 1), 67-78. doi: 10.1113/jphysiol.2003.042598

Goldman-Rakic, P. S. (1994). Working memory dysfunction in schizophrenia. J. Neuropsychiatry Clin. Neurosci. 6, 348-357.

Goldman-Rakic, P. S. (1995). Cellular basis of working memory. Neuron 14, 477-485. doi: 10.1016/0896-6273(95)90304-6

Goldman-Rakic, P. S., Castner, S. A., Svensson, T. H., Siever, L. J., and Williams, G. V. (2004). Targeting the dopamine d1 receptor in schizophrenia: insights for cognitive dysfunction. Psychopharmacology 174, 3-16. doi: 10.1007/s00213004-1793-y

Goldman-Rakic, P. S., Leranth, C., Williams, S. M., Mons, N., and Geffard, M. (1989). Dopamine synaptic complex with pyramidal neurons in primate cerebral cortex. Proc. Natl. Acad. Sci. U.S.A. 86, 9015-9019. doi: 10.1073/pnas.86.22.9015

Gonon, F. (1988). Nonlinear relationship between impulse flow and dopamine released by rat midbrain dopaminergic neurons as studied by in vivo electrochemistry. Neuroscience 24, 19-28. doi: 10.1016/0306-4522(88)90307-7

Graveland, G. A., Williams, R. S., and DiFiglia, M. (1985). A golgi study of the human neostriatum: neurons and afferent fibers. J. Comp. Neurol. 234, 317-333. doi: 10.1002/cne.902340304

Green, A. I., and Halkitis, P. N. (2006). Crystal methamphetamine and sexual sociality in an urban gay subculture: an elective affinity. Cult. Health Sex. 8, 317-333. doi: 10.1080/13691050600783320

Green, M. F. (1996). What are the functional consequences of neurocognitive deficits in schizophrenia? Am. J. Psychiatry 153, 321-330.

Haber, S. N., and Knutson, B. (2010). The reward circuit: linking primate anatomy and human imaging. Neuropsychopharmacology 35, 4-26. doi: 10.1038/npp.2009.129

Haber, S. N., and McFarland, N. R. (1999). The concept of the ventral striatum in nonhuman primates. Ann. N.Y. Acad. Sci. 877, 33-48. doi: 10.1111/j.17496632.1999.tb09259.x

Halkitis, P. N., Parsons, J. T., and Stirratt, M. J. (2001). A double epidemic: crystal methamphetamine drug use in relation to hiv transmission among gay men. $J$. Homosexual. 41, 17-35. doi: 10.1300/J082v41n02_02

Hardingham, G. E., and Bading, H. (2010). Synaptic versus extrasynaptic nmda receptor signalling: implications for neurodegenerative disorders. Nat. Rev. Neurosci. 11, 682-696. doi: 10.1038/nrn2911

Hardingham, G. E., Fukunaga, Y., and Bading, H. (2002). Extrasynaptic nmdars oppose synaptic nmdars by triggering creb shut-off and cell death pathways. Nat. Neurosci. 5, 405-414. doi: 10.1038/nn835

Homayoun, H., and Moghaddam, B. (2006). Progression of cellular adaptations in medial prefrontal and orbitofrontal cortex in response to repeated amphetamine. J. Neurosci. 26, 8025-8039. doi: 10.1523/JNEUROSCI.084206.2006

Horan, W. P., Green, M. F., Knowlton, B. J., Wynn, J. K., Mintz, J., and Nuechterlein, K. H. (2008). Impaired implicit learning in schizophrenia. Neuropsychology 22, 606-617. doi: 10.1037/a0012602
Howells, F. M., Uhlmann, A., Temmingh, H., Sinclair, H., Meintjes, E., Wilson, D., et al. (2014). ${ }^{1} \mathrm{~h}$-magnetic resonance spectroscopy ( ${ }^{1} \mathrm{~h}$-mrs) in methamphetamine dependence and methamphetamine induced psychosis. Schizophr. Res. 153, 122-128. doi: 10.1016/j.schres.2014.01.029

Hu, X. T., and White, F. J. (1997). Dopamine enhances glutamate-induced excitation of rat striatal neurons by cooperative activation of $\mathrm{d} l$ and d2 class receptors. Neurosci. Lett. 224, 61-65. doi: 10.1016/S0304-3940(97) 13443-7

Huntley, G. W., Vickers, J., Janssen, W., Brose, N., Heinemann, S., and Morrison, J. (1994). Distribution and synaptic localization of immunocytochemically identified nmda receptor subunit proteins in sensory-motor and visual cortices of monkey and human. J. Neurosci. 14, 3603-3619.

Iwanami, A., Kato, N., and Nakatani, Y. (1991). P300 in methamphetamine psychosis. Biol. Psychiatry 30, 726-730. doi: 10.1016/0006-3223(91) 90018-H

Iwanami, A., Kuroki, N., Iritani, S., Isono, H., Okajima, Y., and Kamijima, K. (1998). P3a of event-related potential in chronic methamphetamine dependence. J. Nerv. Ment. Dis. 186, 746-751. doi: 10.1097/00005053-19981200000002

Iwanami, A., Suga, I., Kato, N., Nakatani, Y., and Kaneko, T. (1993). Event-related potentials in methamphetamine psychosis during an auditory discrimination task. a preliminary report. Eur. Arch. Psychiatry Clin. Neurosci. 242, 203-208. doi: 10.1007/BF02189964

Iwanami, A., Sugiyama, A., Kuroki, N., Toda, S., Kato, N., Nakatani, Y., et al. (1994). Patients with methamphetamine psychosis admitted to a psychiatric hospital in japan. a preliminary report. Acta Psychiat. Scand. 89, 428-432. doi: 10.1111/j.1600-0447.1994.tb01541.x

Iyo, M., Namba, H., Yanagisawa, M., Hirai, S., Yui, N., and Fukui, S. (1997). Abnormal cerebral perfusion in chronic methamphetamine abusers: a study using 99mtc-hmpao and spect. Prog. Neuro-psychopharmacol. Biol. Psychiatry 21, 789-796. doi: 10.1016/S0278-5846(97)00079-1

Jackson, M. E., Homayoun, H., and Moghaddam, B. (2004). Nmda receptor hypofunction produces concomitant firing rate potentiation and burst activity reduction in the prefrontal cortex. Proc. Natl. Acad. Sci. U.S.A. 101, 8467-8472. doi: 10.1073/pnas.0308455101

Jacobs, E., Fujii, D., Schiffman, J., and Bello, I. (2008). An exploratory analysis of neurocognition in methamphetamine-induced psychotic disorder and paranoid schizophrenia. Cogn. Behav. Neurol. 21, 98-103. doi: 10.1097/WNN.0b013e31816bdf90

Janowsky, D. S., and Risch, C. (1979). Amphetamine psychosis and psychotic symptoms. Psychopharmacology 65, 73-77. doi: 10.1007/BF00491982

Jones, E. G. (1993). Gabaergic neurons and their role in cortical plasticity in primates. Cereb. Cortex 3, 361-372. doi: 10.1093/cercor/3.5.361-a

Kalivas, P. W., and Volkow, N. D. (2005). The neural basis of addiction: a pathology of motivation and choice. Am. J. Psychiatry 162, 1403-1413. doi: 10.1176/appi.ajp.162.8.1403

Kamei, H., Nagai, T., Nakano, H., Togan, Y., Takayanagi, M., Takahashi, K., et al. (2006). Repeated methamphetamine treatment impairs recognition memory through a failure of novelty-induced erk $1 / 2$ activation in the prefrontal cortex of mice. Biol. Psychiatry 59, 75-84. doi: 10.1016/j.biopsych.2005.06.006

Kankaanpää, A., Meririnne, E., Lillsunde, P., and Seppälä, T. (1998). The acute effects of amphetamine derivatives on extracellular serotonin and dopamine levels in rat nucleus accumbens. Pharmacol. Biochem. Behav. 59, 1003-1009. doi: 10.1016/S0091-3057(97)00527-3

Kaufman, A. M., Milnerwood, A. J., Sepers, M. D., Coquinco, A., She, K., Wang, L., et al. (2012). Opposing roles of synaptic and extrasynaptic nmda receptor signaling in cocultured striatal and cortical neurons. J. Neurosci. 32, 3992-4003. doi: 10.1523/JNEUROSCI.4129-11.2012

Kawaguchi, Y. (1995). Physiological subgroups of nonpyramidal cells with specific morphological characteristics in layer ii/iii of rat frontal cortex. J. Neurosci. 15, 2638-2655.

Kemp, J. M., and Powell, T. P. (1970). The cortico-striate projection in the monkey. Brain J. Neurol. 93, 525-546. doi: 10.1093/brain/93.3.525

Kittirattanapaiboon, P., Mahatnirunkul, S., Booncharoen, H., Thummawomg, P., Dumrongchai, U., and Chutha, W. (2010). Long-term outcomes in methamphetamine psychosis patients after first hospitalisation. Drug Alcohol Rev. 29, 456-461. doi: 10.1111/j.1465-3362.2010.00196.x

Koob, G. F., and Bloom, F. E. (1988). Cellular and molecular mechanisms of drug dependence. Science 242, 715-723. doi: 10.1126/science.2903550 
Kuczenski, R., Everall, I. P., Crews, L., Adame, A., Grant, I., and Masliah, E. (2007). Escalating dose-multiple binge methamphetamine exposure results in degeneration of the neocortex and limbic system in the rat. Exp. Neurol. 207, 42-51. doi: 10.1016/j.expneurol.2007.05.023

Langford, D., Adame, A., Grigorian, A., Grant, I., McCutchan, J. A., Ellis, R. J., et al. (2003). Patterns of selective neuronal damage in methamphetamine-user aids patients. J. Acquir. Immune Defic. Syndr. 34, 467-474. doi: 10.1097/00126334200312150-00004

Lee, K. W., Kim, H. C., Lee, S. Y., and Jang, C. G. (2011). Methamphetaminesensitized mice are accompanied by memory impairment and reduction of n-methyl-d-aspartate receptor ligand binding in the prefrontal cortex and hippocampus. Neuroscience 178, 101-107. doi: 10.1016/j.neuroscience.2011.01.025

Lewis, D. A., Curley, A. A., Glausier, J. R., and Volk, D. W. (2012). Cortical parvalbumin interneurons and cognitive dysfunction in schizophrenia. Trends Neurosci. 35, 57-67. doi: 10.1016/j.tins.2011.10.004

Lewis, D. A., Volk, D. W., and Hashimoto, T. (2004). Selective alterations in prefrontal cortical gaba neurotransmission in schizophrenia: a novel target for the treatment of working memory dysfunction. Psychopharmacology 174, 143-150. doi: 10.1007/s00213-003-1673-x

Liu, X., Chang, L., Vigorito, M., Kass, M., Li, H., and Chang, S. L. (2009). Methamphetamine-induced behavioral sensitization is enhanced in the hiv-1 transgenic rat. J. Neuroimmune Pharmacol. 4, 309-316. doi: 10.1007/s11481009-9160-8

Machiyama, Y. (1992). Chronic methamphetamine intoxication model of schizophrenia in animals. Schizophr. Bull. 18, 107-113. doi: 10.1093/schbul/ 18.1.107

Mahoney, J. J., Kalechstein, A. D., Garza, R. D. L., and Newton, T. F. (2008). Presence and persistence of psychotic symptoms in cocaine- versus methamphetamine-dependent participants. Am. J. Addict. 17, 83-98. doi: 10.1080/10550490701861201

Mark, K. A., Quinton, M. S., Russek, S. J., and Yamamoto, B. K. (2007). Dynamic changes in vesicular glutamate transporter 1 function and expression related to methamphetamine-induced glutamate release. J. Neurosci. 27, 6823-6831. doi: 10.1523/JNEUROSCI.0013-07.2007

Mark, K. A., Soghomonian, J. J., and Yamamoto, B. K. (2004). High-dose methamphetamine acutely activates the striatonigral pathway to increase striatal glutamate and mediate long-term dopamine toxicity. J. Neurosci. 24, 11449-11456. doi: 10.1523/JNEUROSCI.3597-04.2004

Maurice, N., Deniau, J.-M., Glowinski, J., and Thierry, A.-M. (1999). Relationships between the prefrontal cortex and the basal ganglia in the rat: physiology of the cortico-nigral circuits. J. Neurosci. 19, 4674-4681.

McKetin, R., Hickey, K., Devlin, K., and Lawrence, K. (2010). The risk of psychotic symptoms associated with recreational methamphetamine use. Drug Alcohol Rev. 29, 358-363. doi: 10.1111/j.1465-3362.2009.00160.x

McKetin, R., McLaren, J., Lubman, D. I., and Hides, L. (2006). The prevalence of psychotic symptoms among methamphetamine users. Addiction 101, 1473-1478. doi: 10.1111/j.1360-0443.2006.01496.x

Medhus, S., Mordal, J., Holm, B., Mørland, J., and Bramness, J. G. (2013). A comparison of symptoms and drug use between patients with methamphetamine associated psychoses and patients diagnosed with schizophrenia in two acute psychiatric wards. Psychiatry Res. 206, 17-21. doi: 10.1016/j.psychres.2012. 09.023

Mizoguchi, H., and Yamada, K. (2011). Pharmacologic treatment with gabab receptor agonist of methamphetamine-induced cognitive impairment in mice. Curr. Neuropharmacol. 9, 109. doi: 10.2174/157015911795016976

Mogenson, G. J., Jones, D. L., and Yim, C. Y. (1980). From motivation to action: functional interface between the limbic system and the motor system. Prog. Neurobiol. 14, 69-97. doi: 10.1016/0301-0082(80)90018-0

Muly, E. C., Szigeti, K., and Goldman-Rakic, P. S. (1998). D1 receptor in interneurons of macaque prefrontal cortex: distribution and subcellular localization. $J$. Neurosci. 18, 10553-10565.

Nagai, T., Takuma, K., Dohniwa, M., Ibi, D., Mizoguchi, H., Kamei, H., et al. (2007). Repeated methamphetamine treatment impairs spatial working memory in rats: reversal by clozapine but not haloperidol. Psychopharmacology 194, 21-32. doi: 10.1007/s00213-007-0820-1

Nagai, T., and Yamada, K. (2010). Molecular mechanism for methamphetamineinduced memory impairment. Nihon Arukoru Yakubutsu Igakkai zasshi 45, 81-91.
Nicola, S. M. (2007). The nucleus accumbens as part of a basal ganglia action selection circuit. Psychopharmacology 191, 521-550. doi: 10.1007/s00213-006-0510-4

Nordahl, T. E., Salo, R., Possin, K., Gibson, D. R., Flynn, N., Leamon, M., et al. (2002). Low n-acetyl-aspartate and high choline in the anterior cingulum of recently abstinent methamphetamine-dependent subjects: a preliminary proton mrs study. magnetic resonance spectroscopy. Psychiatry Res. 116, 43-52. doi: 10.1016/S0925-4927(02)00088-4

Padgett, C. L., Lalive, A. L., Tan, K. R., Terunuma, M., Munoz, M. B., Pangalos, M. N., et al. (2012). Methamphetamine-evoked depression of gaba(b) receptor signaling in gaba neurons of the vta. Neuron 73, 978-989. doi: 10.1016/j.neuron.2011.12.031

Panenka, W. J., Procyshyn, R. M., Lecomte, T., MacEwan, G. W., Flynn, S. W., Honer, W. G., et al. (2013). Methamphetamine use: a comprehensive review of molecular, preclinical and clinical findings. Drug Alcohol Depend. 129, 167-179. doi: 10.1016/j.drugalcdep.2012.11.016

Papadia, S., and Hardingham, G. E. (2007). The dichotomy of nmda receptor signaling. Neuroscientist 13, 572-579. doi: 10.1177/1073858407305833

Paulson, P. E., and Robinson, T. E. (1995). Amphetamine-induced time-dependent sensitization of dopamine neurotransmission in the dorsal and ventral striatum: a microdialysis study in behaving rats. Synapse 19, 56-65. doi: 10.1002/syn.890190108

Petralia, R., Yokotani, N., and Wenthold, R. (1994a). Light and electron microscope distribution of the nmda receptor subunit nmdarl in the rat nervous system using a selective anti-peptide antibody. J. Neurosci. 14, 667-696.

Petralia, R. S., Wang, Y. X., and Wenthold, R. J. (1994b). The nmda receptor subunits nr2a and nr2b show histological and ultrastructural localization patterns similar to those of nr1. J. Neurosci. 14, 6102-6120.

Petralia, R. S. (2012). Distribution of extrasynaptic NMDA receptors on neurons. ScientificWorldJournal 2012:267120. doi: 10.1100/2012/267120

Plüddemann, A., Flisher, A. J., McKetin, R., Parry, C., and Lombard, C. (2010). Methamphetamine use, aggressive behavior and other mental health issues among high-school students in cape town, south africa. Drug Alcohol Depend. 109, 14-19. doi: 10.1016/j.drugalcdep.2009.11.021

Reiner, B. C., Keblesh, J. P., and Xiong, H. (2009). Methamphetamine abuse, hiv infection, and neurotoxicity. Int. J. Physiol. Pathophysiol. Pharmacol. 1, 162-179.

Reubi, J. C., Iversen, L. L., and Jessell, T. M. (1977). Dopamine selectively increases $3 \mathrm{~h}$-gaba release from slices of rat substantia nigra in vitro. Nature 268, 652-654. doi: $10.1038 / 268652 \mathrm{a} 0$

Reubi, J. C., Iversen, L. L., and Jessell, T. M. (1978). Regulation of gaba release by dopamine in the rat substantia nigra. Adv. Biochem. Psychopharmacol. 19, 401-404.

Robinson, T. E., and Becker, J. B. (1986). Enduring changes in brain and behavior produced by chronic amphetamine administration: a review and evaluation of animal models of amphetamine psychosis. Brain Res. 396, 157-198. doi: 10.1016/0165-0173(86)90002-0

Robinson, T. E., and Kolb, B. (1997). Persistent structural modifications in nucleus accumbens and prefrontal cortex neurons produced by previous experience with amphetamine. J. Neurosci. 17, 8491-8497.

Robinson, T. E., and Kolb, B. (1999). Alterations in the morphology of dendrites and dendritic spines in the nucleus accumbens and prefrontal cortex following repeated treatment with amphetamine or cocaine. Eur. J. Neurosci. 11, 1598-1604. doi: 10.1046/j.1460-9568.1999.00576.x

Rymar, V. V., Sasseville, R., Luk, K. C., and Sadikot, A. F. (2004). Neurogenesis and stereological morphometry of calretinin-immunoreactive gabaergic interneurons of the neostriatum. J. Comp. Neurol. 469, 325-339. doi: 10.1002/cne. 11008

Salamone, J. D., Correa, M., Farrar, A., and Mingote, S. M. (2007). Effort-related functions of nucleus accumbens dopamine and associated forebrain circuits. Psychopharmacology 191, 461-482. doi: 10.1007/s00213-006-0668-9

Sato, M., Numachi, Y., and Hamamura, T. (1992). Relapse of paranoid psychotic state in methamphetamine model of schizophrenia. Schizophr. Bull. 18, 115-122. doi: 10.1093/schbul/18.1.115

Schroder, N., O’Dell, S. J., and Marshall, J. F. (2003). Neurotoxic methamphetamine regimen severely impairs recognition memory in rats. Synapse 49, 89-96. doi: 10.1002/syn.10210

Scott, J. C., Woods, S. P., Matt, G. E., Meyer, R. A., Heaton, R. K., Atkinson, J. H., et al. (2007). Neurocognitive effects of methamphetamine: a critical review and meta-analysis. Neuropsychol. Rev. 17, 275-297. doi: 10.1007/s11065-007-9031-0 
Segal, D. S., and Kuczenski, R. (1997). An escalating dose binge model of amphetamine psychosis: behavioral and neurochemical characteristics. J. Neurosci. 17, 2551-2566.

Segal, D. S., and Kuczenski, R. (2001). "Escalating dose-binge exposure to amphetamine and methamphetamine: behavioral and neurochemical characterization," in Contemporary Neuropsychiatry, eds K. Miyoshi, C. Shapiro, M. Gaviria, and Y. Morita (Springer), 330-335.

Sekine, Y., Minabe, Y., Kawai, M., Suzuki, K., Iyo, M., Isoda, H., et al. (2002). Metabolite alterations in basal ganglia associated with methamphetamine-related psychiatric symptoms. a proton mrs study. Neuropsychopharmacology 27, 453-461. doi: 10.1016/S0893-133X(02)00321-4

Selemon, L. D., Begovic, A., Goldman-Rakic, P. S., and Castner, S. A. (2007). Amphetamine sensitization alters dendritic morphology in prefrontal cortical pyramidal neurons in the non-human primate. Neuropsychopharmacology 32, 919-931. doi: 10.1038/sj.npp.1301179

Silber, B. Y., Croft, R. J., Papafotiou, K., and Stough, C. (2006). The acute effects of $\mathrm{d}$-amphetamine and methamphetamine on attention and psychomotor performance. Psychopharmacology 187, 154-169. doi: 10.1007/s00213-006-0410-7

Simon, H., Scatton, B., and Le Moal, M. (1980). Dopaminergic A10 neurones are involved in cognitive functions. Nature 286, 150-151. doi: 10.1038/286150a0

Sirinathsinghii, D., Dunnett, S., Isacson, O., Clarke, D., Kendrick, K., and Björklund, A. (1988). Striatal grafts in rats with unilateral neostriatal lesionsâĂŤii.s in vivo monitoring of gaba release in globus pallidus and substantia nigra. Neuroscience 24, 803-811. doi: 10.1016/0306-4522(88)90068-1

Sora, I., Li, B., Fumushima, S., Fukui, A., Arime, Y., Kasahara, Y., et al. (2009). Monoamine transporter as a target molecule for psychostimulants. Int. Rev. Neurobiol. 85, 29-33. doi: 10.1016/S0074-7742(09)85003-4

Srisurapanont, M., Ali, R., Marsden, J., Sunga, A., Wada, K., and Monteiro, M. (2003). Psychotic symptoms in methamphetamine psychotic in-patients. Int. J. Neuropsychopharmacol. 6, 347-352. doi: 10.1017/S1461145703003675

Srisurapanont, M., Arunpongpaisal, S., Wada, K., Marsden, J., Ali, R., and Kongsakon, R. (2011). Comparisons of methamphetamine psychotic and schizophrenic symptoms: a differential item functioning analysis. Prog. Neuro-Psychopharmacol. Biol. Psychiatry 35, 959-964. doi: 10.1016/j.pnpbp. 2011.01.014

Stephans, S. E., and Yamamoto, B. K. (1994). Methamphetamine-induced neurotoxicity: roles for glutamate and dopamine efflux. Synapse 17, 203-209. doi: 10.1002/syn.890170310

Stephans, S. E., and Yamamoto, B. Y. (1995). Effect of repeated methamphetamine administrations on dopamine and glutamate efflux in rat prefrontal cortex. Brain Res. 700, 99-106. doi: 10.1016/0006-8993(95)00938-M

Sulzer, D., Chen, T. K., Lau, Y. Y., Kristensen, H., Rayport, S., and Ewing, A. (1995). Amphetamine redistributes dopamine from synaptic vesicles to the cytosol and promotes reverse transport. J. Neurosci. 15(5 pt 2), 4102-4108.

Surmeier, D. J., Ding, J., Day, M., Wang, Z., and Shen, W. (2007). D1 and d2 dopamine-receptor modulation of striatal glutamatergic signaling in striatal medium spiny neurons. Trends Neurosci. 30, 228-235. doi: 10.1016/j.tins.2007. 03.008

Tepper, J. M., and Bolam, J. P. (2004). Functional diversity and specificity of neostriatal interneurons. Curr. Opin. Neurobiol. 14, 685-692. doi: 10.1016/j.conb.2004. 10.003

Timmerman, W., and Westerink, B. H. (1997). Electrical stimulation of the substantia nigra reticulata: detection of neuronal extracellular gaba in the ventromedial thalamus and its regulatory mechanism using microdialysis in awake rats. Synapse 26, 62-71. doi: 10.1002/(SICI) 1098-2396(199705)26:1<62::AIDSYN7>3.0.CO;2-C

Tomiyama, G. (1990). Chronic schizophrenia-like states in methamphetamine psychosis. Japan. J. Psychiatry Neurol. 44, 531-539.

Tzschentke, T. (2001). Pharmacology and behavioral pharmacology of the mesocortical dopamine system. Prog. Neurobiol. 63, 241-320. doi: 10.1016/S03010082(00)00033-2

Ujike, H., and Sato, M. (2004). Clinical features of sensitization to methamphetamine observed in patients with methamphetamine dependence and psychosis. Ann. N.Y. Acad. Sci. 1025, 279-287. doi: 10.1196/annals.1316.035
United Nations Office. (2011). "World drug report 2011," in Technical Report (Vienna: United Nations Publications).

Volkow, N. D., Chang, L., Wang, G. J., Fowler, J. S., Ding, Y. S., Sedler, M., et al. (2001a). Low level of brain dopamine $\mathrm{d} 2$ receptors in methamphetamine abusers: association with metabolism in the orbitofrontal cortex. Am. J. Psychiatry 158, 2015-2021. doi: 10.1176/appi.ajp.158.12.2015

Volkow, N. D., Chang, L., Wang, G. J., Fowler, J. S., Leonido-Yee, M., Franceschi, D., et al. (2001b). Association of dopamine transporter reduction with psychomotor impairment in methamphetamine abusers. Am. J. Psychiatry 158, 377-382. doi: 10.1176/appi.ajp.158.3.377

Volkow, N. D., Wang, G. J., Fowler, J. S., Gatley, S. J., Ding, Y. S., Logan, J., et al. (1996). Relationship between psychostimulant-induced high and dopamine transporter occupancy. Proc. Natl. Acad. Sci. U.S.A. 93, 10388-10392. doi: 10.1073/pnas.93.19.10388

Weich, L., and Pienaar, W. (2009). Occurrence of comorbid substance use disorders among acute psychiatric inpatients at stikland hospital in the western cape, south africa. Afr. J. Psychiatry 12, 213-217. doi: 10.4314/ajpsy.v12i3.48496

Williams, S., and Goldman-Rakic, P. (1998). Widespread origin of the primate mesofrontal dopamine system. Cereb. Cortex 8, 321-345. doi: 10.1093/cercor/8.4.321

Wilson, C. J. (1993). The generation of natural firing patterns in neostriatal neurons. Prog. Brain Res. 99, 277-297. doi: 10.1016/S0079-6123(08)61352-7

Wilson, C. J., and Kawaguchi, Y. (1996). The origins of two-state spontaneous membrane potential fluctuations of neostriatal spiny neurons. J. Neurosci. 16, 2397-2410.

Wilson, J. M., Kalasinsky, K. S., Levey, A. I., Bergeron, C., Reiber, G., Anthony, R. M., et al. (1996). Striatal dopamine nerve terminal markers in human, chronic methamphetamine users. Nat. Med. 2, 699-703. doi: 10.1038/ nm0696-699

Xue, C.-J., Ng, J. P., Li, Y., and Wolf, M. E. (1996). Acute and repeated systemic amphetamine administration: effects on extracellular glutamate, aspartate, and serine levels in rat ventral tegmental area and nucleus accumbens. J. Neurochem. 67, 352-363. doi: 10.1046/j.1471-4159.1996. 67010352.x

Yin, H. H., and Knowlton, B. J. (2006). The role of the basal ganglia in habit formation. Nat. Rev. Neurosci. 7, 464-476. doi: 10.1038/nrn1919

Yui, K., Ishiguro, T., Goto, K., and Ikemoto, S. (1997). Precipitating factors in spontaneous recurrence of methamphetamine psychosis. Psychopharmacology 134, 303-308. doi: 10.1007/s002130050453

Yui, K., Ishiguro, T., Goto, K., Ikemoto, S., and Kamata, Y. (1999). Spontaneous recurrence of methampetamine psychosis: increased sensitivity to stress associated with noradrenergic hyperactivity and dopaminergic change. Eur. Arch. Psychiatry Clin. Neurosci. 249, 103-111. doi: 10.1007/s004060050073

Zhang, Y., Loonam, T. M., Noailles, P.-A., and Angulo, J. A. (2001). Comparison of cocaine-and methamphetamine-evoked dopamine and glutamate overflow in somatodendritic and terminal field regions of the rat brain during acute, chronic, and early withdrawal conditions. Ann. N.Y. Acad. Sci. 937, 93-120. doi: 10.1111/j.1749-6632.2001.tb03560.x

Conflict of Interest Statement: The authors declare that the research was conducted in the absence of any commercial or financial relationships that could be construed as a potential conflict of interest.

Received: 03 January 2014; accepted: 01 July 2014; published online: 22 July 2014. Citation: Hsieh JH, Stein DJ and Howells FM (2014) The neurobiology of methamphetamine induced psychosis. Front. Hum. Neurosci. 8:537. doi: 10.3389/fnhum. 2014.00537

This article was submitted to the journal Frontiers in Human Neuroscience. Copyright (c) 2014 Hsieh, Stein and Howells. This is an open-access article distributed under the terms of the Creative Commons Attribution License (CC BY). The use, distribution or reproduction in other forums is permitted, provided the original author(s) or licensor are credited and that the original publication in this journal is cited, in accordance with accepted academic practice. No use, distribution or reproduction is permitted which does not comply with these terms. 